\title{
ALI SE ZAVEDAMO HITROSTI EROZIJSKIH PROCESOV - PRIMER IZ SLOVENSKE ISTRE
}

\author{
Matija Zorn \\ Geografski inštitut Antona Melika ZRC SAZU, Gosposka ulica I3, \\ SI-I000 Ljubljana, Slovenija \\ e-mail: matija.zorn@zrc-sazu.si
}

Izvirni znanstveni članek

COBISS 1.01

\section{Izvleček}

Predstavljene so meritve erozijsko-denudacijskih procesov v porečju Dragonje. Meritve so obsegale površinsko spiranje na treh različnih rabah tal, umikanje strmih golih flišnih pobočij, premikanje gradiva po erozijskem jarku in kemično denudacijo v porečju. Meritve so potekale od februarja 2005 do maja 2006. Namen članka je opozoriti na hitrost nekaterih geomorfnih procesov, zaradi katere bi bilo treba bolj poudariti njihov pomen pri oblikotvornosti površja.

Ključne besede: geomorfologija, pedogeografija, erozijski procesi, erozija prsti, umikanje pobočij, Slovenija, slovenska Istra, Dragonja.

\section{ARE WE AWARE OF THE SPEED OF EROSION PROCESSES - AN EXAMPLE FROM SLOVENE ISTRIA}

\begin{abstract}
Measurements of erosion and denudation processes in Dragonja river basin are presented. Measured were interrill erosion on three different land uses, rockwall retreat on steep flysch slopes, movements of debris in erosion gully and chemical denudation. Measurements took place between February 2005 and May 2006. The purpose of the article is to draw attention to the speed of some geomorphic processes. Due to this, we should lay more stress upon their role in morphogenesis of the landscape.
\end{abstract}

Key words: geomorphology, pedogeography, erosion processes, soil erosion, rockwall retreat, Slovenia, Slovene Istria, Dragonja. 


\section{UVOD}

V porečjih rečno-denudacijskega reliefa (Gabrovec in Hrvatin 1998, 80) potekajo različni erozijsko-denudacijski procesi hkrati, toda ali se zavedamo, kakšna je njihova hitrost ter kakšna so razmerja med njimi?

Natek $(1983,54)$ je pred četrt stoletja zapisal: »Posledica specifične usmerjenosti slovenske geomorfologije $\mathrm{v}$ proučevanje nekaterih skupnih oblik (sledovi poledenitev, predkvartarne in kvartarne uravnave ter terase, kraški pojavi) je, da se nekaterim oblikam ni posvečalo nobene pozornosti. Predvsem to velja za fluvio-denudacijske oblike, še zlasti pa za oblike ploskovnega in linearnega odnašanja na pobočjih«. Stanje se od takrat ni kaj bistveno spremenilo.

Da bi povečali védenje o geomorfnih procesih na rečno-denudacijskem reliefu, smo v porečju Dragonje od februarja 2005 do maja 2006 merili hitrosti štirih erozijsko-denudacijskih procesov: površinskega spiranja na treh različnih rabah tal, umikanja strmih golih flišnih pobočij, premikanja gradiva po erozijskih jarkih erozijskih žarišč in kemično denudacijo v porečju.

\section{MERITVE}

Erozijsko-denudacijske procese kvantificiramo z meritvami ali pa uporabimo različne modele (Stroosnijder 2005, 162-163).

Meritve opravljamo v laboratoriju ali na terenu. Prednosti laboratorijskih raziskav so, da omogočajo boljši nadzor nad »odvisnimi spremenljivkami« (npr. vremenskimi pogoji), kot tudi uporabo boljših merilnih naprav in možnost ponavljanja meritev. Prednosti terenskih meritev pa so v možnostih opravljanja meritev v pravem merilu, na »pravi« prsti in v pravih vegetacijskih pogojih, s pravimi časovnimi spremembami in okoljskimi spremenljivkami (Stroosnijder 2005, 163).

Pri meritvah je potrebno opredeliti primerne merske metode, saj se te razlikujejo glede na merilo, dolžino meritev, finančna sredstva itd. Stroosnijder $(2005,164)$ razlikuje pet velikostnih kategorij za preučevanje vodne erozije: »točkovno« merilo $\left(1 \mathrm{~m}^{2}\right)$ za preučevanje površinskega spiranja, merilo erozijskih polj $\left(<100 \mathrm{~m}^{2}\right)$ za preučevanje žlebične erozije, pobočje $(<500 \mathrm{~m})$ za preučevanje erodiranja in odlaganja gradiva, merilo »polja $(<1 \mathrm{ha})$ za preučevanje erozijskih jarkov/kanalov in merilo majhnih porečij $(<50$ ha). Stroosnijder $(2005$, 164) razlikuje tudi dve časovni merili: en deževni dogodek in letno povprečje, Loughran $(1989,216)$ pa razlikuje merilo deževnega dogodka in kakršenkoli »drug primeren časovni interval«.

Naše meritve erozije prsti, sproščanja fliša in premikanja gradiva po erozijskem jarku so potekale tedensko, vzorčenja vode za ugotavljanje kemične denudacije pa mesečno. Za merjenje površinskega spiranja smo po Stroosnijderju $(2005,164)$ uporabili »točkovno merilo«, za sproščanje fliša merilo erozijskih polj, za premikanje gradiva po erozijskem jarku pa merilo »polja«. Po Poesenu in ostalih $(1994,141)$ smo za merjenje površinskega spiranja uporabili majhna (»mikro«) erozijska polja, za sproščanje fliša srednje velika (»mezo«) erozijska polja, za premikanje gradiva po erozijskem jarku pa velika (»makro«) erozijska polja. 
Predvsem za sproščanje fliša je pomembno, da je bila v obdobju meritev povprečna letna minimalna temperatura zraka v Kopru za $1,4{ }^{\circ} \mathrm{C}$ nižja, povprečna zimska minimalna temperatura pa kar za 2,4 ${ }^{\circ} \mathrm{C}$ nižja od dolgoletnega povprečja (1961-1990; Klimatografija... 1995, 274; Agencija Republike Slovenije za okolje 2006). Za vodno erozijo je pomembno, da je bila količina padavin na portoroškem letališču v času meritev višja od večletnega povprečja (1991-2005) za skoraj 60 mm oziroma 6 \% v obdobju februar 2005-april 2006 in slabih 85 mm oziroma 8,2 \% v obdobju maj 2005-april 2006. Glede na večletno povprečje (19912005) je bila v času meritev drugačna tudi sezonska razporeditev padavin z okrog $30 \%$ padavin jeseni (Povzetki... 2007; Agencija Republike Slovenije za okolje 2007).

\section{I Površinsko spiranje}

Za meritve te vrste erozije prsti, t. j. odstranjevanje delcev prsti in preperine $\mathrm{z}$ naravnimi agensi, marsikje pospešeno zaradi delovanja človeka (goloseki, čezmerna paša, poti) in živali, ki je intenzivnejše od nastajanja prsti (Komac in Zorn 2005, 75; Zorn in Komac 2005, 164), smo uporabili zaprta erozijska polja. Slabost takšnih polj je, da ni pritoka vode in erodiranega gradiva iznad erozijskega polja (Stroosnijder 2005, 167) in zato tudi ni pravih naravnih razmer (Loughran 1989, 217), posebno zaradi t.i. »robnih pogojev«. Takšne raziskave morajo biti »dolgotrajne«, meritve pa morajo zaradi večje zanesljivosti rezultatov potekati na čim več erozijskih poljih hkrati. Zavedati se je tudi treba, da majhna zaprta polja ponavadi precenjujejo dejansko erozijo ob ekstrapolaciji na večje prostorske enote, saj ne upoštevajo sedimentacije znotraj večjih prostorskih enot (Collins in Walling 2004, 171-172). Velikost takšnih polj je znana, zato se erozijo lahko izrazi $\mathrm{v} \mathrm{kg} / \mathrm{m}^{2} \mathrm{v}$ določenem času ob predpostavki, da je »erozija enakomerna po vsem polju« (Loughran 1989, 217).

Naša erozijska polja so bila velika $1 \mathrm{~m}^{2}$, meritve pa so potekale na osmih erozijskih poljih. Dve erozijski polji smo postavili na golo prst v oljčnik s povprečnim naklonom $5,5^{\circ}$, dve na travnik s povprečnim naklonom $9,4^{\circ}$ in štiri $v$ gozd (dve na pobočje s povprečnim naklonom $7,8^{\circ}$ in dve na pobočje s povprečnim naklonom $21,4^{\circ}$ ).

$\mathrm{Na}$ goli prsti se s površinskim spiranjem letno sprosti do $9 \mathrm{~kg}$ prsti $/ \mathrm{m}^{2}$, na travniku do $170 \mathrm{~g} / \mathrm{m}^{2}$, v gozdu z manjšim naklonom do $390 \mathrm{~g} / \mathrm{m}^{2}$ in $\mathrm{v}$ gozdu z večjim naklonom do $415 \mathrm{~g} / \mathrm{m}^{2}$. Na goli prsti se je površje v času meritev znižalo za skoraj centimeter, v gozdu ni doseglo niti pol milimetra, na travniku pa je bilo zanemarljivo in je znašalo slabo petino milimetra (Preglednica 1). V preglednici 5 ekstrapoliramo merjene vrednosti na daljša časovna obdobja. V desetih letih lahko na goli prsti pričakujemo znižanje površja do $9 \mathrm{~cm}, \mathrm{~V}$ sto letih pa celo do slabega metra. V gozdu ne glede na naklon lahko v sto letih pričakujemo znižanje površja za okrog $4 \mathrm{~cm}$, na travniku po dober centimeter in pol.

$\mathrm{Ob}$ teh podatkih se pojavi vprašanje ali se različna hitrost erozije prsti (oz. zniževanja površja) po nekaj sto letih pozna v morfologiji pokrajine? Dejstvo je, da se reliefne spremembe na obdelovalnih površinah dogajajo, kot sta pokazala Komac in Zorn (2005, 84; Zorn in Komac 2005, 171) na primeru njive v porečju Besnice pri Kranju. Ponekod v Sloveniji obdelava zemljišč na istih mestih poteka že 1000 in več let. Mason $(1995,190)$ na primer za okolico Adlešičev v Beli krajini piše, da se je na spodnji terasi zaradi erozije iz zgornje terase v zgodovinski dobi odložil »štiri metre širok depozit«. 
Preglednica 1: Površinsko spiranje in zniževanja površja na različnih rabah tal v obdobju 28.4.2005-26.4.2006 (Zorn 2007).

Table 1: Interril erosion and surface lowering according to land use in the period 28. 4. 2005-26. 4. 2006 (Zorn 2007).

\begin{tabular}{|l|c|c|c|c|c|c|}
\hline \multirow{2}{*}{} & \multicolumn{3}{|c|}{ Gola prst } & \multicolumn{3}{c|}{ Travnik } \\
\cline { 2 - 7 } & \multicolumn{2}{|c|}{ Erozija prsti } & $\begin{array}{c}\text { Zniževanje } \\
\text { površja }\end{array}$ & \multicolumn{2}{|c|}{ Erozija prsti } & $\begin{array}{c}\text { Zniževanje } \\
\text { površja }\end{array}$ \\
\cline { 2 - 7 } & $\mathrm{g} / \mathrm{m}^{2}$ & $\mathrm{~kg} / \mathrm{ha}$ & $\mathrm{mm}$ & $\mathrm{g} / \mathrm{m}^{2}$ & $\mathrm{~kg} / \mathrm{ha}$ & $\mathrm{mm}$ \\
\hline $\begin{array}{l}\text { Povprečno na teden } \\
(12 \text { mesecev })\end{array}$ & 173,34 & 1733,35 & 0,16 & 3,23 & 32,34 & 0,003 \\
\hline $\begin{array}{l}\text { Skupaj } \\
(12 \text { mesecev })\end{array}$ & 9013,43 & $90.134,31$ & 8,54 & 168,15 & 1681,51 & 0,16 \\
\hline
\end{tabular}

\begin{tabular}{|l|c|c|c|c|c|c|}
\hline \multirow{2}{*}{} & \multicolumn{3}{|c|}{ Gozd - manjši naklon } & \multicolumn{3}{c|}{ Gozd - večji naklon } \\
\cline { 2 - 7 } & Erozija prsti & $\begin{array}{c}\text { Zniževanje } \\
\text { površja }\end{array}$ & \multicolumn{2}{|c|}{ Erozija prsti } & $\begin{array}{c}\text { Zniževanje } \\
\text { površja }\end{array}$ \\
\cline { 2 - 7 } & $\mathrm{g} / \mathrm{m}^{2}$ & $\mathrm{~kg} / \mathrm{ha}$ & $\mathrm{mm}$ & $\mathrm{g} / \mathrm{m}^{2}$ & $\mathrm{~kg} / \mathrm{ha}$ & $\mathrm{mm}$ \\
\hline $\begin{array}{l}\text { Povprečno na teden } \\
(12 \text { mesecev) }\end{array}$ & 7,52 & 75,22 & 0,01 & 7,98 & 79,78 & 0,01 \\
\hline $\begin{array}{l}\text { Skupaj } \\
(12 \text { mesecev) }\end{array}$ & 391,15 & 3911,49 & 0,37 & 414,87 & 4148,68 & 0,39 \\
\hline
\end{tabular}

Slika 1: Erozijsko polje na goli prsti v oljčniku in gradivo ujeto v lovilno posodo v tednu med 7.4. in 13.4.2005 (foto: M. Zorn).

Figure 1: Erosion plot on bare land in an olive grove with collected weekly eroded material and runoff (7. 4. 2005-14. 4. 2005; photo: M. Zorn).

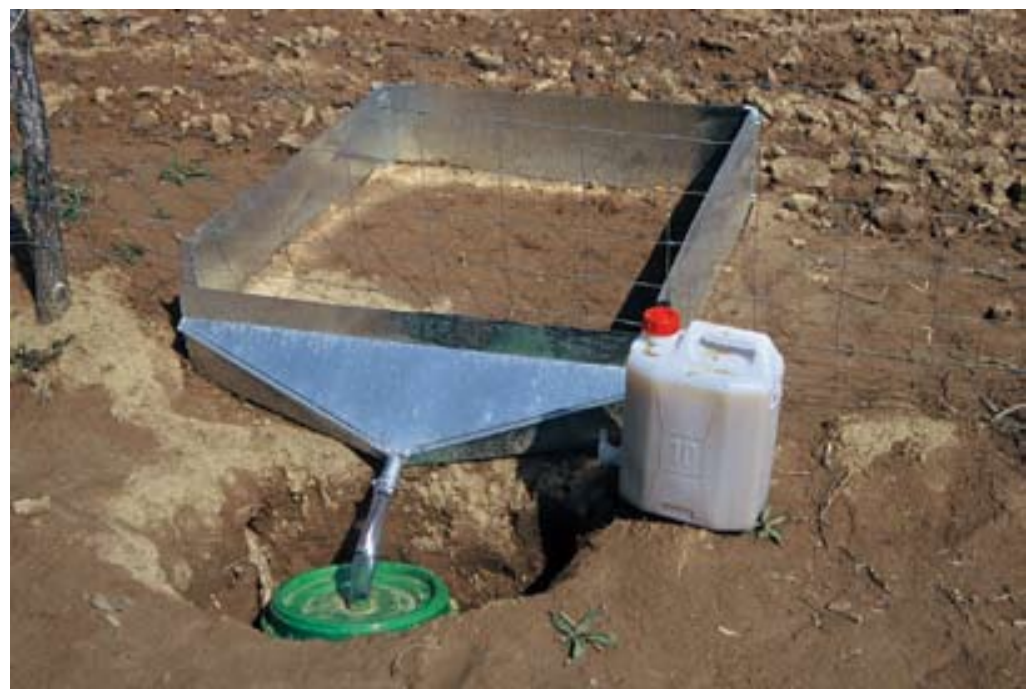




\subsection{Sproščanje fliša}

Strma gola pobočja, ki so hkrati tudi erozijska žarišča, so morfogenetska posebnost flišnega dela Istre. Obstajajo linijske - to so erozijski jarki ali struge hudournikov, ki imajo »V« obliko (poglavje 2.3), in ploskovne oblike - te so lahko v obliki strmih sten ali v obliki rebrastega reliefa na položnejših pobočjih (Jurak in Fabić 2000, 606). Prebivalci območja med Dragonjo in Rokavo imenujejo erozijska žarišča »bržine« (Kodarin 1998, 2).

Stene erozijskih žarišč niso gladke, temveč »drobno nazobčane zaradi različno odpornih flišnih plasti. Ker peščenci počasneje razpadajo od vmesnih laporjev, štrlijo v značilnih zobcih po več centimetrov iz stene. [...] Zaradi neodpornosti flišnih plasti tudi klifi [oz. strma flišna pobočja, op. p.] niso obstojni« (Radinja 1973, 78). Sama izoblikovanost teh pobočij »opozarja, kako se flišne stene ne razvijajo in ne umikajo enakomerno « (Radinja 1973, 82). Iz sten močneje štrlijo odpornejše debelejše plasti peščenjaka, ki pa po Radinji $(1973,78)$ za razvoj pobočij niso nič bolj pomembne od ostalih plasti, saj so pretrte in se kmalu po spodjedanju odlomijo.

Slika 2: Pol odprti erozijski polji za merjenje sproščanja fliša (foto: M. Zorn).

Figure 2: Half-open erosion plots for flysch rockwall retreat measurements (photo: M. Zorn).

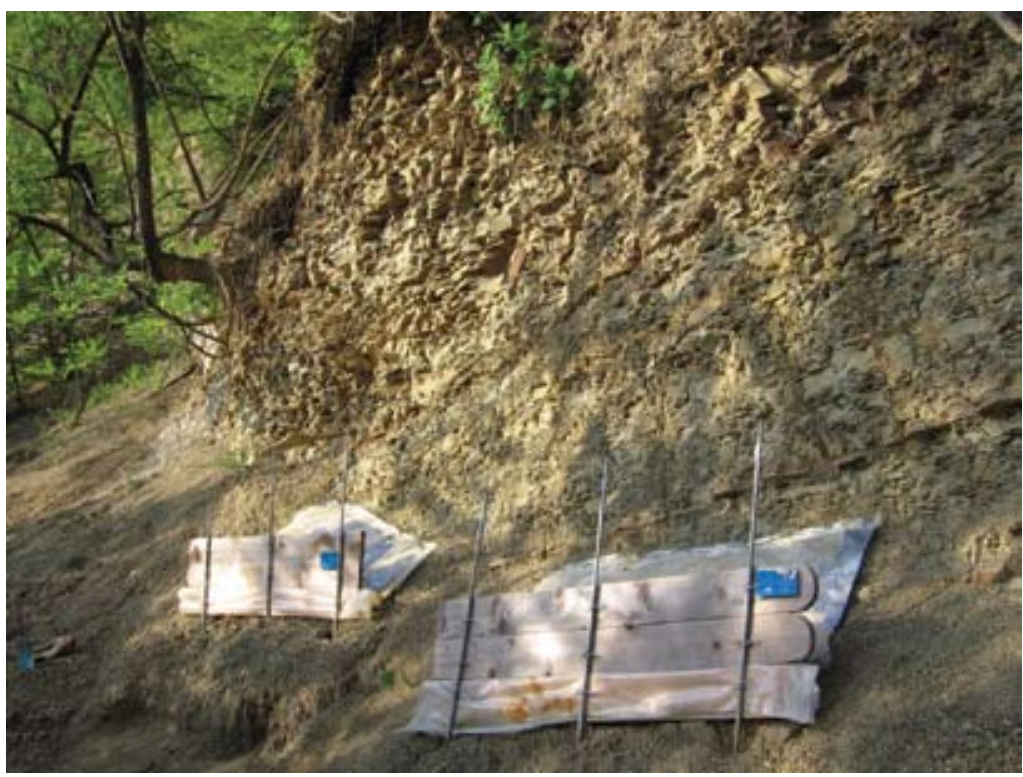

Erozijske procese na erozijskih žariščih v notranjosti slovenske Istre sta do naših meritev preučevala Ogrin (1992) in Petkovšek (2002). Erozijske procese na obalnih klifih pa so preučevali Gams (1970/71), Radinja (1973), Šribar (1967) in Žumer (1990). Radinja (1973, 85) je na primer ocenil umikanje obalnih klifov na 1-2 cm/leto, Ogrin $(1992,118)$ pa umikanje pobočij na erozijskem žarišču v Bržaniji na $2 \mathrm{~cm} /$ leto. 
Pri naših meritvah smo uporabili pol odprta erozijska polja. Pol odprta, ker so bila omejena z robom pobočja na vrhu polja (torej zaprta od zgoraj), odprta pa so bila ob straneh. Postavili smo štiri erozijska polja $\mathrm{z}$ velikostjo prispevnih površin $1,8-4,5 \mathrm{~m}^{2}$.

Sproščanje gradiva je $\mathrm{v}$ obdobju 28.4.2005-26.4.2006 znašalo $84,26 \mathrm{~kg} / \mathrm{m}^{2}$ na leto. $\mathrm{V}$ tem času se je pobočje umaknilo za skoraj $5 \mathrm{~cm}$, $\mathrm{v}$ sto letih pa bi umik pobočja znašal skoraj $5 \mathrm{~m}$ (Preglednica 5).

Preglednica 2: Sproščanje flišnih kamnin in umikanje pobočja v obdobju 28.4.2005-26.4.2006 (Zorn 2007).

Table 2: Rockwall retreat on steep flysch slopes in the period from 28. 4. 2005 to 26. 4. 2006 (Zorn 2007).

\begin{tabular}{|l|c|c|c|}
\hline \multirow{2}{*}{} & \multicolumn{3}{|c|}{ Sproščanje fliša } \\
\cline { 2 - 4 } & $\mathrm{kg} / \mathrm{m}^{2}$ & $\mathrm{~kg} / \mathrm{ha}$ & $\mathrm{mm}$ \\
\hline Povprečno na teden (12 mesecev) & 1,62 & $16.203,47$ & 0,95 \\
\hline Skupaj (12 mesecev) & 84,26 & $842.580,20$ & 49,22 \\
\hline
\end{tabular}

\subsection{Premikanje gradiva po erozijskem jarku}

Strma gola pobočja ne predstavljajo le flišne stene (70-90 naklona; poglavje 2.2), pač pa tudi že razjedena pobočja z erozijskimi žlebiči in jarki. Erozijski jarki so položnejši od sten (naklon $50-60^{\circ}$ ), na njih pa so »denudacijski in erozijski procesi markantnejši od mehaničnega razpadanja« (Radinja 1973, 79).

Erozijski jarki nastajajo s kanaliziranjem površinskega toka, predvsem tam, kjer so že reliefno (naravno) zasnovane linije odtoka, pa tudi ob raznih antropogenih oblikah (npr. izkopih, njivskih brazdah, mejah parcel, poteh in cestah). V nasprotju s površinskim spiranjem in žlebično erozijo, pri katerih se gradivo večinoma odlaga že na samem pobočju ali ob njegovem vznožju, je pri jarkovni eroziji več možnosti, da erodirano gradivo doseže vodotoke v dnu dolin.

Za meritve jarkovne erozije ni po Poesenu in Hookeju (1997, 174) »standardizirane metodologije«, kot tudi ne »univerzalnega modela«. Težave so že pri določitvi velikosti erozijskih jarkov, saj so te kot pišeta Wainwright in Thornes $(2004,179) »$ deloma subjektivne«, še največkrat pa se za njihovo spodnjo mejo uporablja ploščina preseka jarka $>900 \mathrm{~cm}^{2}(30$ x $30 \mathrm{~cm})$.

Preglednica 3: Premikanje sproščenih flišnih kamnin po erozijskem jarku v obdobju 28.4.200526.4.2006 (Zorn 2007).

Table 3: Movements of flysch rocks in the erosion gully in the period from 28. 4. 2005 to 26. 4. 2006 (Zorn 2007).

\begin{tabular}{|l|c|c|c|}
\hline & $\mathrm{kg} / \mathrm{m}^{2}$ & $\mathrm{~kg} / \mathrm{ha}$ & $\begin{array}{c}\text { Umikanje pobočij } \\
(\mathrm{mm})\end{array}$ \\
\hline Povprečje na teden (12 mesecev) & 0,28 & 2738,86 & 0,16 \\
\hline Skupaj (12 mesecev) & 14,46 & $145.159,70$ & 8,48 \\
\hline
\end{tabular}


Za merjenje premikanja gradiva po erozijskem jarku smo uporabili zaprto erozijsko polje, saj smo s pregrado zaprli celotno prispevno površino, ki je bila velika 0,1 ha.

V obdobju 28.4.2005-26.4.2006 so bili premiki v erozijskem jarku slabih $15 \mathrm{~kg} / \mathrm{m}^{2}$ na leto, kar pomeni, da so se pobočja v jarku umaknila za približno 8,5 mm. Ekstrapolacija na sto let kaže na umikanje pobočij v jarku za slab meter (Preglednica 5).

Slika 3: Zaprto erozijsko polje za merjenje premikanja gradiva po erozijskem jarku - s pregrado zaprta celotna prispevna površina (foto: M. Zorn).

Figure 3: Closed erosion plot for measurements of flysch rocks movements in the erosion gully - the whole hinterland is closed with a dam (photo: M. Zorn).

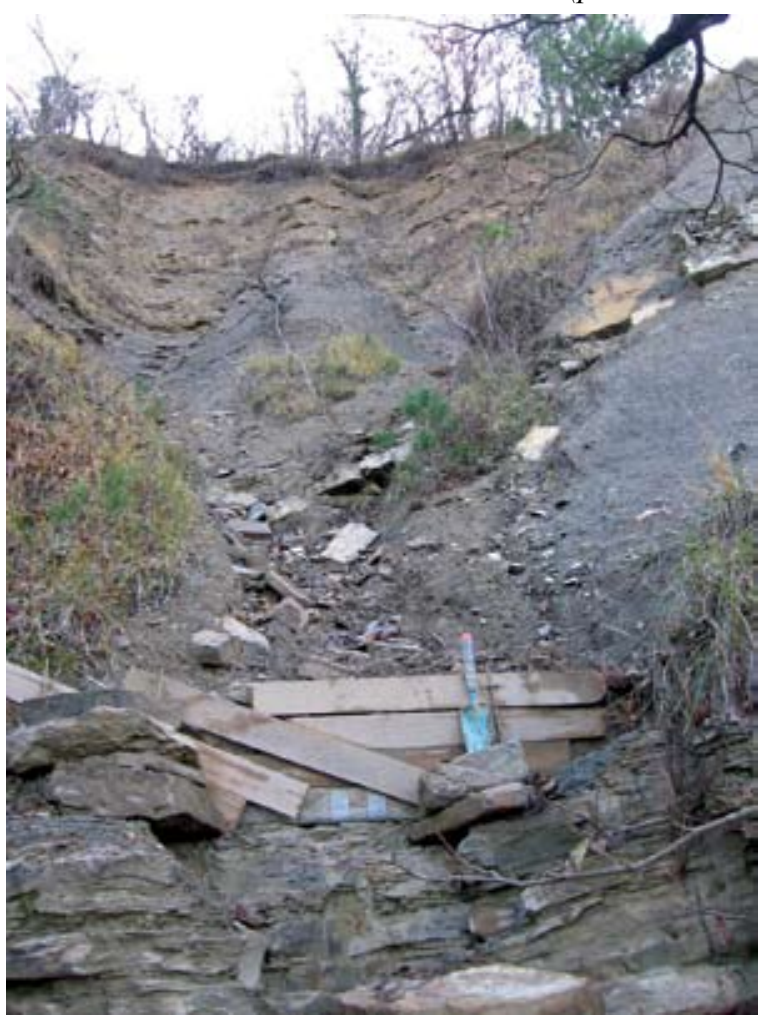

\subsection{Kemična denudacija}

»Kemična denudacija« je po Summerfieldu $(1994,8)$ denudacija, kjer poteka »odstranjevanje ... raztopljenega gradiva«. Največkrat se meri na kraškem reliefu, kjer proces imenujemo »kraška denudacija« (Gams 1974, 60) ali »korozijska intenziteta« (Kunaver 1978, 35). Ker pa proces ni omejen le na kraški relief, uporablja Gams $(1998,58)$ tudi širši pojem »kemična erozija«. 
Za ugotavljaje kemične denudacije $\mathrm{v}$ porečju Dragonje smo enkrat na mesec merili trdoto vode pri vodomerni postaji pod Kaštelom. Pri ugotavljanju trdote vode v vodi merimo količino raztopljenih snovi predvsem kalcijevih $\left(\mathrm{Ca}^{2+}\right)$ in magnezijevih $\left(\mathrm{Mg}^{2+}\right)$ ionov. Poleg omenjenih je $\mathrm{v}$ vodi raztopljenih še nekaj drugih snovi, ki pa jih pri naših meritvah nismo upoštevali. Po Habiču $(1968,216)$ so to meritve letnega »odnašanja raztopljenih karbonatov«. Da so takšne meritve v porečju Dragonje sploh smiselne, je vzrok v visoki vrednosti karbonatov $\mathrm{v}$ flišnih kamninah.

Podatke o celokupni trdoti voda v zahodni in južni Sloveniji navaja Gams $(1974,68$; 2003, 73). Navaja tudi trdote voda flišnih vodotokov v slovenski Istri, ki so glede na trdote voda na kraškem reliefu relativno visoke. Trdote vode iz flišnih izvirov v Bovški kotlini navaja Komac $(2000,67-71)$ in piše, da »imajo višjo skupno, kalcijevo in magnezijevo trdoto kot izviri na apnencu« (Komac 2001, 39).

Naši rezultati kažejo, da se zaradi kemične denudacije površje v porečju Dragonje znižuje s hitrostjo $66 \mathrm{~mm}$ na 1000 let. Po podatkih Gamsa $(1974,68 ; 2003,73)$ pa se površje v porečju Dragonje znižuje s hitrostjo $62 \mathrm{~mm}$ na 1000 let (Preglednica 5).

\subsection{Primerjava meritev}

Najhitrejši so procesi na strmih golih flišnih pobočjih (pobočja se umikajo skoraj $5 \mathrm{~cm} /$ leto), sledijo erozijski jarki, pri katerih se pobočja odmikajo okrog $8,5 \mathrm{~mm} /$ leto, s približno enako hitrostjo pa poteka tudi zniževanje površja zaradi medžlebične erozije na goli flišni prsti (Opomba: razlika v količini erodiranega gradiva (preglednica 5) med erozijskim jarkom in golo prstjo se pri izračunu zniževanja površja zabriše zaradi različne specifične gostote fliša in prsti na flišu). Za faktor 130 (oziroma prek 200 pri primerjavi sproščanja) je zniževanje površja počasnejše $\mathrm{v}$ gozdu kot umikanje strmih flišnih pobočjih. Umikanje strmih flišnih pobočjih je za faktor okrog 300 (oziroma prek 500 pri primerjavi sproščanja) hitrejše od zniževanja površja na travniku. Najpočasnejša je kemična denudacija, ki je kar za faktor 744 počasnejša od umikanja strmih flišnih pobočij.

Slika 4: Hitrost različnih erozijsko-denudacijskih procesov (28.4.2005-26.4.2006) (Zorn 2007). Figure 4: Intensity of different erosional-denudational processes in the period from 28. 4. 2005 to 26. 4. 2006) (Zorn 2007).

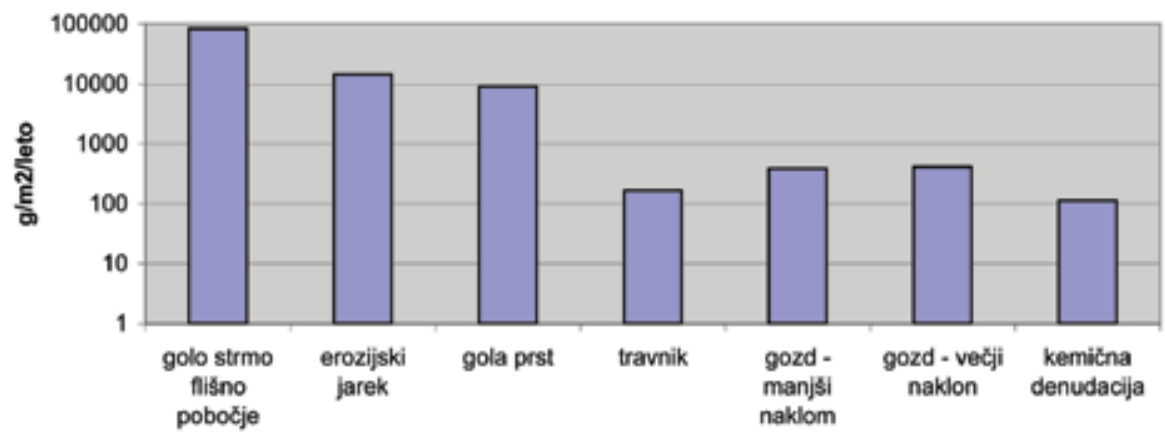


Preglednica 4: Hitrost različnih erozijsko-denudacijskih procesov in razmerja med njimi (28.4.2005-26.4.2006) (Zorn 2007).

Table 4: Intensity of different erosional-denudational processes and relations between them in the period from 28. 4. 2005 to 26. 4. 2006 (Zorn 2007).

\begin{tabular}{|c|c|c|c|c|c|c|c|}
\hline & 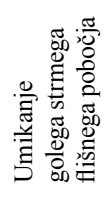 & 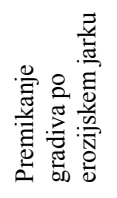 & 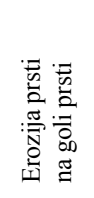 & 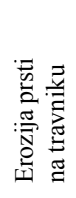 & 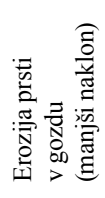 & 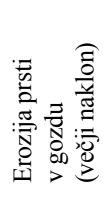 & 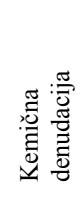 \\
\hline $\begin{array}{l}\text { Specifično sproščanje } \\
\left(\mathrm{g} / \mathrm{m}^{2} / \text { leto }\right)\end{array}$ & $84.258,02$ & $14.455,27$ & 9013,43 & 168,15 & 391,15 & 414,8 & 113,32 \\
\hline $\begin{array}{l}\text { Razmerje glede na } \\
\text { golo strmo flišno pobočje }\end{array}$ & 1 & 0,17 & 0,11 & 0,002 & 0,005 & 0,005 & 0,001 \\
\hline $\begin{array}{l}\text { Razmerje glede na } \\
\text { erozijski jarek na golem } \\
\text { strmem flišnem pobočju }\end{array}$ & 5,83 & 1 & 0,62 & 0,01 & 0,03 & 0,03 & 0,008 \\
\hline $\begin{array}{l}\text { Razmerje glede na } \\
\text { erozijo prsti na goli prsti }\end{array}$ & 9,35 & 1,60 & 1 & 0,02 & 0,04 & 0,046 & 0,013 \\
\hline $\begin{array}{l}\text { Razmerje glede na } \\
\text { erozijo prsti na travniku }\end{array}$ & 501,09 & 85,97 & 53,60 & 1 & 2,33 & 2,47 & 0,67 \\
\hline $\begin{array}{l}\text { Razmerje glede na } \\
\text { erozijo prsti v gozdu } \\
\text { (manjšsi naklon) }\end{array}$ & 215,41 & 36,96 & 23,04 & 0,43 & 1 & 1,06 & 0,29 \\
\hline $\begin{array}{l}\text { Razmerje glede na } \\
\text { erozijo prsti v gozdu } \\
\text { (večji naklon) }\end{array}$ & 203,10 & 34,84 & 21,73 & 0,41 & 0,94 & 1 & 0,27 \\
\hline $\begin{array}{l}\text { Razmerje glede na } \\
\text { kemično denudacijo }\end{array}$ & 743,53 & 127,56 & 79,54 & 1,48 & 3,45 & 3,66 & 1 \\
\hline
\end{tabular}

Slika 5: Zniževanje površja/umikanje pobočij zaradi različnih erozijsko-denudacijskih procesov (28.4.2005-26.4.2006) (Zorn 2007).

Figure 5: Surface lowering/rockwall retreat due to different erosional-denudational processes (28. 4. 2005-26. 4. 2006) (Zorn 2007).

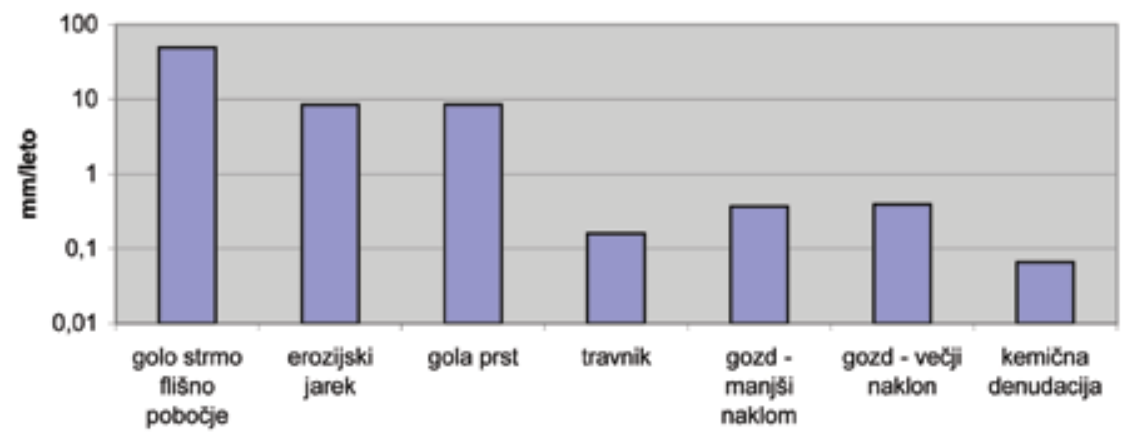


Preglednica 5: Zniževanje površja/umikanje pobočij zaradi navedenega dejavnika v daljšem časovnem obdobju, ob predpostavki, da so pogoji takšni kot so bili v času meritev (28.4.200526.4.2006) (Zorn 2007).

Table 5: Surface lowering/rockwall retreat according to prevailing controlling factor in different time spans - supposing that the conditions would be the same as in the time of the measurements (28. 4. 2005-26. 4. 2006) (Zorn 2007).

\begin{tabular}{|l|c|c|c|c|c|c|c|}
\hline \multirow{2}{*}{ V ... letih } & $\begin{array}{c}\text { Gtrma flišna } \\
\text { pobočja }\end{array}$ & $\begin{array}{c}\text { Erozijski } \\
\text { jarek }\end{array}$ & Gola prst & Travnik & $\begin{array}{c}\text { Gozd } \\
- \text { manjši } \\
\text { naklon }\end{array}$ & $\begin{array}{c}\text { Gozd - večji } \\
\text { naklonje }\end{array}$ & $\begin{array}{c}\text { Kemčna } \\
\text { denudacija }\end{array}$ \\
\cline { 2 - 8 } & Umikanje & $\begin{array}{c}\text { Zniževanje } \\
\text { površja }\end{array}$ & $\begin{array}{c}\text { Zniževanje } \\
\text { površja }\end{array}$ & $\begin{array}{c}\text { Zniževanje } \\
\text { površja }\end{array}$ & $\begin{array}{c}\text { Zniževanje } \\
\text { površja }\end{array}$ & $\begin{array}{c}\text { Zniževanje } \\
\text { površja }\end{array}$ \\
\hline 1 & $\mathrm{~m}$ & $\mathrm{~m}$ & $\mathrm{~m}$ & $\mathrm{~m}$ & $\mathrm{~m}$ & $\mathrm{~m}$ & $\mathrm{~m}$ \\
\hline 10 & 0,049 & 0,009 & 0,0085 & 0,0002 & 0,0004 & 0,0004 & 0,066 \\
\hline 100 & 0,49 & 0,09 & 0,085 & 0,002 & 0,004 & 0,004 & 0,66 \\
\hline 1000 & 4,92 & 0,85 & 0,854 & 0,016 & 0,037 & 0,039 & 6,62 \\
\hline 10.000 & 49,22 & 8,48 & 8,54 & 0,16 & 0,37 & 0,39 & 66,19 \\
\hline
\end{tabular}

\section{SKLEP}

Ob ekstrapolaciji podatkov na daljša časovna obdobja vidimo, da se je moral relief že samo v zgodovinski dobi precej spremeniti. Še hitreje se je spreminjal v pleistocenu, ko so bili geomorfni procesi še intenzivnejši. Glede na hitrost umikanja strmih golih flišnih pobočij v erozijskih žariščih lahko prečni prerez doline širine okrog enega kilometra, kot je na primer V porečju Rokave med Marezigami oziroma Babiči in Glemom, nastane že v približno 20.000 letih (oziroma polovico hitreje, če sta erozijski žarišči na obeh straneh doline).

Če so erozijska žarišča nastala ob človeških posegih v pokrajino, potem so se takšna pobočja umaknila za nekaj deset metrov, a če verjamemo De Ploeyju (1992), ki jim pripisuje starost med 2700 in 40.000 let, potem je njihova oblikotvornost zelo pomembna. To bi pomenilo, da za hitro širitev dolin v flišu ni nujna le močna rečna erozija kot posledica neotektonskega dviganja (po Premruju (2005, 338-339) so »vertikalni premiki« v slovenski Istri 2-4 mm/leto).

Obdobje naših meritev je bilo po količini padavin in po nizkih temperaturah (oziroma prehodih iz negativnih $\mathrm{v}$ pozitivne temperaturne) nadpovprečno, zato naše meritve lahko pomenijo nadpovprečno sproščanje. Po drugi strani pa so bile, če starost erozijski žarišč sega v pleistocen, takrat vremenske razmere še ekstremnejše.

Ob navedenih hitrostih spreminjanja rečno-denudacijskega reliefa, je potrebno pri njegovi oblikotvornosti bolj poudariti pomen erozijsko-denudacijskih procesov. 


\section{Viri in literatura}

Collins, A. L., Walling, D. E. 2004. Documenting catchment suspended sediment sources: problems, approaches and prospects. Progress in Physical Geography, 28, 2, 159-196.

De Ploey, J. 1992. Gullying and age of badlands: an application of the erosional susceptibility model E. Catena, Supplement, 23, 31-45.

Gabrovec, M., Hrvatin, M. 1998. Površje. V: Geografski atlas Slovenije: Država v prostoru in času, 80-83. Ljubljana.

Gams, I. 1970/71. Severna obala Strunjanskega polotoka. Proteus, 33, 2, 56-62. Ljubljana.

Gams, I. 1974. Kras: zgodovinski, naravoslovni in geografski oris. Ljubljana.

Gams, I. 1998. Kras. V: Geografija Slovenije, 55-90. Ljubljana.

Gams, I., 2003. Kras v Sloveniji v prostoru in času. Ljubljana.

Habič, P. 1968. Kraški svet med Idrijco in Vipavo: prispevek k poznavanju razvoja kraškega reliefa. Dela, 21. Ljubljana.

Jurak, V., Fabić, Z. 2000: Erozija kišom u slivu bujičnog vodotoka u središnjoj Istri. V: Zbornik radova: 2. hrvatski geološki kongres, 603-612. Zagreb.

Klimatografija Slovenije 1961-1990: Temperature zraka. 1995. Hidrometeorološki zavod republike Slovenije. Ljubljana.

Kodarin, D. 1998. Med Rokavama: v besedi in sliki. Boršt.

Komac, B. 2000. Vodne razmere kraških izvirov na južnem podnožju Kaninskega pogorja. Diplomsko delo. Oddelek za geografijo Filozofske fakultete. Ljubljana.

Komac, B. 2001. The karst springs of the Kanin massif. Geografski zbornik, 41, 7-43. Ljubljana.

Komac, B., Zorn, M. 2005. Soil erosion on agricultural land in Slovenia - measurements of rill erosion in the Besnica valley. Acta geographica Slovenica, 45, 1, 53-86. Ljubljana.

Kunaver, J. 1978. Intenzivnost zakrasevanja in njegovi učinki v zahodnih Julijskih Alpah - Kaninsko pogorje. Geografski vestnik, 50, 33-50. Ljubljana.

Loughran, R. J. 1989. The measurement of soil erosion. Progress in Physical Geography, 13, 2, 216-233.

Mason, P. F. J. 1995. Neolitska in eneolitska naselja v Beli krajini: naselja v Gradcu in izraba prostora v času od 5. do 3. tisočletja BC. Poročilo o raziskovanju paleolitika, neolitika in eneolitika v Sloveniji, 22, 183-199.

Natek, K. 1983. Metoda izdelave in uporabnost splošne geomorfološke karte. Magistrsko delo. Oddelek za geografijo Filozofske fakultete. Ljubljana.

Ogrin, D. 1992. Dendrogeomorphological analysis of erosion processes - two case studies from Koprsko primorje (Slovenia). V: Proceedings of the International Symposium »Geomorphology and Sea« and the Meeting of the Geomorphological Commission of the Carpatho-Balkan Countries, 115-118. Zagreb.

Petkovšek, G. 2002. Kvantifikacija in modeliranje erozije tal z aplikacijo na povodju Dragonje. Doktorsko delo. Fakulteta za gradbeništvo in geodezijo. Ljubljana.

Poesen, J. W. A., Hooke, J. M. 1997. Erosion, flooding and channel management in Mediterranean environments of southern Europe. Progress in Physical Geography, 21, 2, 157-199. 
Poesen, J. W., Torri, D., Bunte, K. 1994. Effects of rock fragments on soil erosion by water at different spatial scales: a review. Catena, 23, 1-2, 141-166.

Povzetki klimatoloških analiz; letne in mesečne vrednosti za nekatere postaje v obdobju 1991-2005: Portorož. 2007. Ljubljana, Agencija Republike Slovenije za okolje. Medmrežje: http://www.arso.gov.si/podro cja/vreme_in_podnebje/podnebje/Porto-roz.pdf (8.1. 2007).

Premru, U. 2005. Tektonika in tektogeneza Slovenije: geološka zgradba in geološki razvoj Slovenije. Ljubljana.

Radinja, D. 1973. Prispevek k spoznavanju recentnega abrazijskega reliefa na primeru Strunjanske obale. V: Mednarodni mladinski raziskovalni tabori 1971-1972. Ljubljana, Republiški koordinacijski odbor gibanja »Znanost mladini«, 72-94.

Šribar, V. 1967. Nekatere geomorfološke spremembe pri Izoli, dokumentirane z arheološkimi najdbami. Geologija, 10, 271-277. Ljubljana.

Stroosnijder, L. 2005. Measurement of erosion: Is it possible. Catena, 64, 2-3, 162-173.

Summerfield, M. A. 1994. Global Geomorphology. Harlow.

Wainwright, J., Thornes, J. B. 2004. Environmental Issues in the Mediterranean: Processes and perspectives from the past and present. London.

Zorn, M. 2007. Recentni geomorfni procesi na rečno-denudacijskem reliefu na primeru porečja Dragonje. Doktrosko delo. Oddelek za geografijo Filozofske fakultete. Ljubljana.

Zorn, M., Komac, B. 2005. Erozija prsti na kmetijskih zemljiščih v Sloveniji. Ujma, 19, 163174. Ljubljana.

Žumer, J. 1990. Recentni razvoj klifov na obalah Istrske Slovenije. V: Geomorfologija in geoekologija,143-147. Ljubljana.

\section{ARE WE AWARE OF THE SPEED OF EROSION PROCESSES - AN EXAMPLE FROM SLOVENE ISTRIA}

\section{Summary}

Different erosion processes are going on simultaneously in river basins. Are we aware of their speed and ratio between them?

Between February 2005 and May 2006 we measured four different erosion and denudation processes in Dragonja river basin: interrill erosion on three different land uses, rockwall retreat on steep flysch slopes, movements of debris in erosion gully and chemical denudation.

The fastest among all measured erosion processes was rockwall retreat on steep flysch slopes, with rockwall retreat speed of almost $5 \mathrm{~cm} /$ year. The second fastest were processes in erosion gully, where processes were almost six times slower. Surface lowering due to interrill erosion on bare flysch soil has about the same speed as processes in erosion gully (around $8.5 \mathrm{~mm}$ /year). Relative to rockwall retreat, surface lowering is 130 times slower in the forest and around 300 times slower on meadows. The slowest process is chemical denudation -744 times slower than rockwall retreat. 
With extrapolation of data on longer time periods it is obvious that relief should have been (due to these processes) altered already in historical times. The changes were even faster during Pleistocene, when geomorphic processes were even more intense.

If we take into account these speeds of erosion processes, it is necessary to renew interpretation of evolution of relief in the studied area. 